\title{
The Physics of Dissent and the Effects of Movement Momentum
}

\section{Citation}

Chenoweth, Erica, and Margherita Belgioioso. 2019. The Physics of Dissent and the Effects of Movement Momentum. Nature Human Behaviour 3, no. 10: 1088-095.

\section{Permanent link}

http://nrs.harvard.edu/urn-3:HUL.InstRepos:42332888

\section{Terms of Use}

This article was downloaded from Harvard University's DASH repository, and is made available under the terms and conditions applicable to Open Access Policy Articles, as set forth at http:// nrs.harvard.edu/urn-3:HUL.InstRepos:dash.current.terms-of-use\#OAP

\section{Share Your Story}

The Harvard community has made this article openly available.

Please share how this access benefits you. Submit a story.

Accessibility 


\title{
The Physics of Dissent and the Effects of Movement Momentum
}

Erica Chenoweth 1 *, Margherita Belgioioso2

\begin{abstract}
How do people power movements succeed when modest proportions of the population participate? We propose that the effects of social movements increase as they gain momentum. We approximate a simple law drawn from physics: momentum equals mass times velocity $(\mathrm{p}=\mathrm{mv})$. We propose that the momentum of dissent is a product of participation (mass) and the number of protest events in a week (velocity). We test this simple physical proposition against panel data on the potential effects of movement momentum on irregular leader exit in African countries between 1990-2014 using a variety of estimation techniques. Our findings show that social movements potentially compensate for relatively modest popular support by concentrating their activities in time, thereby increasing their disruptive capacity. Crucially, these findings also provide a straightforward way for dissidents to easily quantify their coercive potential by assessing their participation rates and increased concentration of their activities in time.
\end{abstract}

1 Harvard Kennedy School, Harvard University, Cambridge, MA, USA.

2 Department of Politics and History, Brunel University London, London, England, UK.

*Correspondence author. Email contact: erica_chenoweth@hks.harvard.edu. 
From East Germany to the Philippines, Tunisia, Burkina Faso, Armenia, Algeria, and Sudan, people-power movements often topple entrenched regimes with surprisingly peaceful efficacy_even when relatively small numbers of people participate. How do movements succeed when modest proportions of the population participate? Although a recent experimental study identified a $25 \%$ tipping point in the ability of coordinated groups to revise or overthrow existing systems1, free-riding behavior often prevents movements from mobilizing more than $5 \%$ of a country's population2. Yet strikingly, most mass uprisings that have mobilized $3.5 \%$ of the population against dictatorships have nevertheless succeeded in overthrowing them (E. Chenoweth, The Surprising Success of Nonviolent Resistance, TEDxBoulder, September 21, 2013)4—far less than critical mass thresholds of 10-25\% tipping points identified in prior studies $1,4,5,6$. We propose that the momentum of dissent is a product of participation (mass) and the number of protest events in a week (velocity) $(\mathrm{p}=\mathrm{mv})$. We test the correlation between movement momentum and irregular leader exit in African countries between 1990-2014. Our findings show that movement momentum is significantly correlated with irregular leader departure. Crucially, these findings provide a straightforward way for dissidents to easily quantify their coercive potential by assessing their participation rates and increased concentration of their activities in time.

Although extant research finds that large numbers of participants increase the chances of movement success 3 , the impact of participation on the effectiveness of civil resistance movements is based on reported peak participation, rather than dynamic ebbs and flows of participation. For instance, Chenoweth and Stephan3 identify a million participants in the People Power movement in the Philippines, rather than capturing the number of reported participants in each of the hundreds of protest events linked to that movement from 19831986. Accounting only for peak participation rates neglects the effect of dynamic participation on the success of civil resistance campaigns over time. In other words, there is 
no ability to understand how changing levels of participation may have contributed to Ferdinand Marcos' departure. Additionally, existing research is generally poor at identifying the timing of success for social movements. Most existing studies, in fact, use yearly data on different features of movements and their opponents3. As such, researchers have not yet understood how movements effectively build initiative in ways that tip them over into success - particularly in the face of repression. The characteristics of successful social movements are better understood than their dynamics.

In this article, we advance two core propositions. First, we argue that, although the size of participation is indeed a crucial determinant of the success of mass uprisings, it is an incomplete indicator of movement potential. Instead, we argue that movement momentum may be essential to understanding the strength of mass mobilization. We argue that momentum is determined by both the number of participants and the concentration of dissident activities in time: the interaction between movement size and velocity. Second, we propose that the momentum movements deploy on a daily basis is strongly correlated with major political changes. We find support for these intuitions by testing them on irregular leader exits in African countries between 1990-2014. Although the research design does not allow us to make causal claims, our findings suggest that nonviolent dissidents may be able to use insights from physics to leverage publicly-accessible indicators to estimate the momentum they can bring to bear against their adversaries on any given day.

We turn to a simple analogy from physics - that momentum equals mass times velocity $(\mathrm{p}=\mathrm{mv})$ - to show how activists can estimate their momentum using publicly-available indicators. In social movements, one proxy for mass is the number of observed participants in nonviolent events (including protests, strikes, sit-ins, demonstrations, marches, and other nonviolent methods3,7. We introduce a proxy for velocity, which we operationalize as the number of protests observed in a given week. We estimate momentum by multiplying the 
number of observed participants per thousand people in the national population by the number of protest events in the week prior to the current day. We operationalize mass, velocity, and momentum using various alternative measures, including a logarithmic transformation of the mass indicator; see the discussion in the methods section below.

There are many reasons to assume that the momentum of mobilization-rather than just mass participation - is an important driver of major political and social changes. We expect that momentum creates repeated and visibly unrelenting interactions between dissidents and state elites, which may elicit key defections among ruling elites. Often, economic elites, state media authorities, cultural authorities, or civilian bureaucrats refuse to continue cooperating with regime leadership during periods of mass discontent. These loyalty shifts among key elites - typically sparked by mass mobilization — are often the lynchpin in securing the victory of months- or year-long mass movements. Such mechanisms have proved critical to successful mass movements around the world. For example, in 1980s and 1990s South Africa, mass protests, consumer boycotts, and international sanctions and divestments from abroad were ultimately so economically and politically disruptive that white business elites demanded that the Apartheid regime negotiate with the African National Congress.

Movement momentum — where large numbers of dissidents amass over a sustained period, rather than just in a one-off event-may be particularly influential in convincing security forces to end their cooperation with the incumbent regime. As large numbers of dissidents persist in concentrated mass mobilizations, momentum may make repression more politically costly, leading security forces to rethink their loyalties. The fact that security force behaviour is often important in determining the outcomes of mass movements is wellestablished in the literature on social movement success3,7,8. For instance, in October 2000, protestors in Serbia mobilized after fraudulent elections against Slobodan Milosevic. Police officers ultimately refused to obey orders to fire on demonstrators or abandoned their posts, 
recognizing members of their own communities or families in the crowd. Protestors then stormed the Parliament, and Milosevic fled the country and conceded the election to the opposition leader. We have observed similar dynamics in countries as diverse as the Philippines (1986), Tunisia (2010), and Iran (1979).

What is less understood is how movements have built critical mass to activate such behavior. We suggest that as the momentum of mass mobilization increases - as a function of the mass of participants and velocity of nonviolent dissent - pressure may increase among the population and among elites to demand or orchestrate a change in national leadership.

We articulate the following hypothesis:

Hypothesis: Movement momentum—-mass times velocity—is positively correlated with the likelihood of movement success.

\section{Results}

We test this proposition by estimating the potential effect of the momentum of nonviolent dissent on the relative risk of leadership irregular exit through a newly compiled dataset of country-day observations in Africa from 1990-2014. Our unit of analysis is the country-day, reflecting our focus on temporally granulated contentious dynamics, rather than structural or time-invariant characteristics of states and of non-state actors. Our dataset builds on the Social Conflict Analysis Database (SCAD)9, which includes information on participation and occurrence of protests, riots, strikes, inter-communal conflict, government violence against civilians, and other forms of social conflict not systematically tracked in other conflict datasets, as well as the ARCHIGOS dataset10, which identifies the manner by which rulers leave political power. To obtain the dependent variable, we looked for instances in which the leader lost power through irregular means, defined as leader removal "in contravention of explicit rules and established conventions"10. This form of exit is exceedingly rare, occurring 
only 45 times out of over 295,000 observations in Africa between January 1, 1990 and January 1, 2014. We then conducted additional desk research on each instance to produce a strict measure that excludes cases of leader irregular exit due to assassinations or coups that appeared to be part of internal political maneuvers or personal vendettas outside of the underlying context of popular revolts. Our strict measure of irregular leader exit therefore includes only the 24 cases of irregular leader exits that occurred in otherwise peaceful contexts but where dissidents had called for the incumbent national leader to step down at some point in the prior three months.

The resulting dependent variable is a dichotomous variable equal to 1 when a leader loses power through irregular means and 0 otherwise. Table 1 reports the cases and the primary mechanism of departure. As one can see from the data, in almost all cases, security forces or civilian elites shifted their loyalties, resulting in the leader's departure, further supporting our assumptions above. Of course, such loyalty shifts may have occurred in some cases without resulting in irregular leader departure, but Table 1 illustrates the mechanism at work in prior studies of mass movement outcomes.

To construct a dynamic variable for movement mass, we first generated a dichotomous variable equal to 1 when a nonviolent event occurs and 0 if otherwise. We obtained this indicator by extracting information from the variable "etype" in SCAD9,11. We coded as nonviolent events organized demonstrations, spontaneous demonstrations, general strikes and limited strikes, and riots because the common denominator of each of these event types is the intended use of peaceful means to obtain a political goal. We excluded events where an identifiable armed group engages in acts of violence, such as hit-and-run attacks, shootings, or bombings.

We then created a variable that measures the average number of participants in each event by extracting information from the "npart" variable in SCAD, which is based on a 
seven-point scale ranging from very low participation (less than ten people) to very high participation (over a million). We generated the variable mass to approximate the number of observed participants in nonviolent events per thousand people in the country's national population. Our indicator of mass ranges from 0 to 132.634 participants per thousand $(\mathrm{mean}=.165, \mathrm{sd}=2.094)$. Because of the non-normal distribution of this variable, we also created an alternate logged version of this variable, which we then standardized (by adding 10 to each value) to yield only positive values. This indicator ranges from .508 to 14.888 $($ mean $=8.238, \mathrm{sd}=3.022)$. We note that the indicator drops all instances where no participants were observed in the current observation, yielding a much smaller sample conditional on (a) the occurrence of an event; and (b) some nonzero number of participants observed.

We next derived a variable for the velocity of events. To obtain this, we counted the total number of events of nonviolent dissent in the seven days preceding the current countryday. This indicator ranges from 0 to 189 (mean=48.405, $\mathrm{sd}=46.329)$.

Because momentum equals mass times velocity, we then created the interaction term momentum, which multiplies the mass and velocity of dissent for the current day. It ranges in value from 0 to 5649 (mean=6.463, $\mathrm{sd}=70.05)$. We also created an alternate measure of momentum that multiples the logged values of mass and velocity of dissent. This indicator ranges from 2.667 to 2195.354 (mean=469.367, $\mathrm{sd}=380.009)$.

Because some scholars consider riots a form of violent dissent7, we created strict measures of mass, velocity, and momentum, which exclude riots and include only nonviolent methods of dissent, like protests and strikes.

We implement a series of control variables that capture other factors that might affect the likelihood of leadership irregular exit. First, we control for the absolute change in the number of locations where nonviolent events took place by extracting information from the variable "sublocal" in SCAD11, which provides a numerical count of the individual localities 
where nonviolent dissent took place. We expect this variable to have a positive impact on the likelihood of irregular leader change as incidences of resistance become more widespread throughout the country.

Second, we expect that repression discourages dissent, therefore making events rarer over time12. However, higher levels of repression of nonviolent dissent might also be more likely to backfire, increase participation in the future, and elicit defections by security forces, thereby increasing the likelihood of political change8,13,14. We extract an indicator of repression from $\mathrm{SCAD}_{11}$, coded as 1 if security forces use nonlethal coercion against dissidents, 2 if security forces used lethal repression against dissidents, and 0 if otherwise.

Third, because civil wars are relatively rarer in our sample than low-intensity violence, we also construct a variable measuring the number of violent events in the prior week based on event type 8 from the SCAD database, which we expect to be associated with a decreased likelihood of irregular leader change3,15,16.

Additionally, widespread poverty may create economic grievances that undermine state capacity for effective response and generate or reinforce elite-level conflict with the government17,18,19. We therefore include a measure of logged GDP per capita (logged)20, which we expect to have a positive association with the likelihood of irregular leader exit. Finally, we include a measure of logged total state population 20 to account for the fact that states with larger populations tend to have higher likelihoods of political instability21,22,23,24.

We estimate rare event logistic regression models on irregular leader exit because such outcomes occur in just $.0001 \%$ of the observations under study. Table 2 presents eight model specifications. The models generally support our hypothesis, showing that the potential effect of momentum is generally positive and significant regardless of whether we use the general measure (Models 1, 3, and 4), rare events logit models on the full sample (Models 1 and 3) or restricting the pool of observations in which an event occurred (Models 4, 5, and 6), and both 
the normal measure of mass (Models 1, 3, and 4) and the logged measure of mass (Model 6). We do not find evidence of a significant association when we exclude riots from the sample (Models 2 and 7), although violent events alone are not significantly correlated with irregular leader exit (Model 8). Likelihood ratio tests and Wald tests suggest that including the momentum indicator significantly improves model performance in all of the models.

The substantive correlation between momentum and the predicted probability of irregular leader exit are considerable - the probability more than triples from the minimum to the maximum values - although as a rare event, the absolute values of the predicted probabilities are fairly modest. To illustrate the association between momentum and irregular leader exit, we plot the predicted probabilities of such exits only on days in which a protest takes place based on the rare events conditional logistic regression performed in Model 4. Figure 1 plots the predicted probability of irregular leader exit at different values of velocity, when mass mobilization equals $1.5 \%, 3.5 \%$, or $5 \%$ of national population size.

We note that most of the statistically significant observations come at upper ranges of the interaction term (e.g. when velocity is greater than 160 and mass mobilization is greater than $3.5 \%$ of the population), suggesting that the relationship between momentum and irregular leader exit is most relevant at the upper bounds of mass and velocity. Because mass mobilization rarely occurs at such significant levels, we draw on Model 6, in which mass is logged, to plot the marginal effects of velocity on irregular leader exit given quantile values of logged mass (Figure 2), correcting for the non-normality of the mass indicator.

Figure 2 further supports the finding that when mass is at its highest value - constituting about 132 people per thousand, or $13.263 \%$ of the national population - the probability of irregular leader exit surpasses $60 \%$ at the highest levels of velocity. Moreover, at the highest participation rates, the probability of irregular leader exit increases at a velocity of 40 events 
per week (observations that exceed this value represent the 58th percentile of cases in our sample).

However, it is important to note that below the 75 th percentile of mass $(0.138 \%$ of the national population size) and the median value of velocity27, the probability of irregular leader exit on any given day remains low. When velocity is set at or below the median value of 28 events per week, no levels of mass increased the probability of success for nonviolent movements. This is consistent with the fact that both large-scale mass mobilization and irregular leader exit are rare events, as well as the fact that these figures are based on the conservative assumption that a protest occurs on the same day as the leader departs.

Notably, in no observations did participation exceed $13.3 \%$ of the national population, thus making the $25 \%$ threshold of participation identified in prior studies 1 moot in this regional sample. However, the findings also demonstrate that in the rare cases where over $3.5 \%$ of the national population does mobilize at a high velocity, the predicted probability of irregular leader exit increases substantially. Taken together, these statistical and substantive results provide an important corrective to existing studies which suggest that peak participation rates alone are sufficient to tip the balance to success 1,2,4,5,6.

With regard to the other covariates, the diffusion of nonviolent dissent has a positive association across four of the seven models, providing support for our intuition that more widespread diffusion of events is associated with greater disruptive potential25. Second, in Models 3 and 8, we find no credible evidence that violent events have a systematic correlation with leadership departure, consistent with prior studies3,7,16. Population size is negatively and significantly associated across all models, showing that larger countries experience fewer irregular leader exits. Moreover, GDP per capita has no association, suggesting that the potential effects of momentum are robust across countries with varying levels of economic development. Finally, the coefficient for repression is consistently positive and statistically 
significant: a greater number of repressive incidents correlates with a higher risk of irregular leader exit. This finding might provide evidence in support for a backfire process leading to security forces defection $3,7,8,13$, or represent an endogenous process, whereby the most threatening mass mobilizations are those that both respond to and elicit higher rates of repression15. Experimental studies or those that can account for endogenous processes could further assess these possibilities. However, importantly, higher instances of repression by state forces does not appear to undermine the strong positive correlation between movement momentum and leadership change. In summary, we find robust evidence that momentum — or mass times velocity—has a notable association with the likelihood of irregular leader exit. The potential effect of momentum does not change depending on control variables or a vast series of model specifications.

\section{Discussion}

There are several important limitations to the current study. First, the findings address correlation and not causation, by the nature of the data and design; additional research could address causal processes more directly. Second, we test our propositions on data from one region because of data availability on our core variables of interest; however, we believe that the insights derived from the African context can apply more generally and recommend further research to probe their generalizability around the world when reliable global data become available. Third, we note here that irregular leader exit does not necessarily result in equitable, peaceful, or stable outcomes, nor does it guarantee that movement success obtains in the long term. Further research could assess the degree to which irregular leader exits induced by mass resistance yield such outcomes, although some existing work suggests that when mass resistance is primarily nonviolent, transitions to democracy are more common than when resistance is violent $3,26,27,28$. Fourth, we were not able to assess whether transnational actors - 
such as foreign governments, international organizations, international media, transnational solidarity networks, or the private sector - have influence on either the capacity of dissidents to organize consistently, or the decision calculus of the leaders and their pillars of support. Data collection regarding attempts at such impact could further research in this area as well, although we caution that existing research finds little support for the notion that powerful foreign states can effectively back nonviolent resistance movements without undermining their vital, local bases of support3. Finally, our research design limits us to understanding the correlation between momentum and irregular leader exit on any given day; it does not assess the cumulative impacts of mobilization over a longer term, nor does it evaluate threshold effects specifically. Future work could attempt to study these relationships more dynamically.

Despite these limitations, our study points to three important insights. First, movements mobilizing a relatively modest proportion of the population have increased their disruptive potential when they concentrate high-participation nonviolent activities in time. Such nonviolent events are not limited to protests: many involve a diverse array on nonviolent techniques, such as strikes, boycotts, and other forms of mass non-cooperation. Yet for movements and activists attempting to assess their potential for political change, momentum equals mass times velocity. Second, the momentum of the movements under study was more dependent upon their own resources, organization, and stamina than on the opponent's response. In this regard, our findings suggest that movements can in fact increase their momentum by planning numerous nonviolent mass mobilizations in concentrated intervals in sequence. And the momentum of the movement in such instances is not likely to be diminished by the way the state responds. Finally, these findings also shed light on a simple and yet farreaching fact regarding social movement mobilization: activists may be able to estimate their absolute levels of momentum by taking into account the number of participants in current events as well as how many events occur in relatively short periods of time. The more people 
involved, and the more concentrated nonviolent events become in time, the more momentum the movements have. And, although we cannot specify a causal relationship, our results show that high levels of momentum significantly correlate with a high likelihood that the leader exits through irregular means across a large number of robustness checks. This intuitive yet elegant metric should be accessible to many people who are engaged in activism on the ground and seek a better sense of how strong their movements are becoming day to day.

\section{Methods}

We rely on panel data to study the correlation between movement momentum and irregular leader exit in African countries between 1990-2014. We use a variety of estimation techniques. No statistical methods were used to pre-determine sample sizes, but our sample sizes are considerably larger than those reported in previous publications.2,3,8

Measurement. We describe the construction of our variables in the main text however, we offer some additional details on several measures here. To develop the dependent indicator for irregular leader exit, we extract the variable "EXIT" in ARCHIGOS and retain only the instances of leaders losing power through irregular means, defined as leader removal "in contravention of explicit rules and established conventions"10, and typically due to conflicts between domestic forces involving the threat or use of contentious political activities, popular revolts, coups, and assassinations, as well as cases where external intervention or warfare resulted in the leader's removal. In the text above, we report findings based on the strict measure of 24 irregular leader exits only. In the Supplementary Information, we report findings based on the measure of all 45 irregular leader exits; the findings are consistent with our overall analysis.

To construct our variable for mass, we rely on the Npart variable from SCAD 11 as well as an indicator of annual national population size from the World Bank.20 Npart measures the 
total number of participants in each event as follows: $1=$ less than $10 ; 2=10$ to $100 ; 3=101$ to 1,$000 ; 4=1,001$ to 10,$000 ; 5=10,001$ to 100,$000 ; 6=100,001$ to $1,000,000 ; 7=$ over $1,000,00011$. We set the number of participants to 9 for the "very low" category and to $1,000,001$ for the "very high" category, while simply taking the average number of participants for all the remaining intervals in the scale. We then divided the total number of daily participants in protest by the national population size and normalized the variable to reflect participants per thousand for ease of interpretation.

Statistical analyses. We estimate rare event logistic regression models on irregular leader exit because such outcomes occur in just $.0001 \%$ of the observations under study. In several models, we estimate conditional logistic regression on irregular leader exit, which estimates the models only in cases where dissidents are observed protesting in the current observation. For all models, we include a cubic polynomial approximation using a variable on the years since the last leader irregular exit to correct for time dependence, since leader irregular exits are more likely to recur when there is a recent history of leader irregular exit 11,21. Two-tailed tests are applied. We cluster standard errors by country since the variance may differ systematically across states. Likelihood ratio tests are performed on logistic regressions of the model, and Wald tests are performed on rare events logistic regressions of the model. Finally, we estimate the variance inflation factor (VIF) and find no evidence of multicollinearity among our covariates; the correlation coefficients across all variables likewise show low correlations across all covariates. The results are consistent across various additional robustness checks and alternative specifications, which are included in the Supplementary Information.

Reporting Summary. Further information on research design is available in the Nature Research Reporting Summary linked to this article.

Data availability: The STATA dataset that supports the findings of this study are publicly available for download from the Harvard Dataverse: https://doi.org/10.7910/DVN/JYM19E. Correspondence and requests for materials should be addressed to E.C or M.B. 
Code availability: The custom code that supports the findings of this study are publicly available for download from the Harvard Dataverse: https://doi.org/10.7910/DVN/JYM19E. Correspondence. Correspondence and requests for materials should be addressed to E.C or M.B. 


\section{References}

1. D. Centola, J. Becker, D. Brackbill, A. Baronchelli, Science 360, 1116-1119 (2018).

2. M. Lichbach, The Rebel's Dilemma (Univ. of Michigan Press, 1994).

3. E. Chenoweth, M. Stephan, Why Civil Resistance Works: The Strategic Logic of Nonviolent Conflict (Columbia University Press, 2011).

4. R. M. Kanter, Am. J. Sociol. 82, 965-990 (1977).

5. D. Dahlerup, Scand. Polit. Stud. 11, 275-298 (1988).

6. G. Marwell, P. Oliver, The Critical Mass in Collective Action (Cambridge Univ. Press, 1993).

7. G. Sharp, The Politics of Nonviolent Action (Porter Sargent, 1973).

8. J. Sutton, C. Butcher, I. Svensson, J. of Peace Research 51, 553-573 (2014).

9. I. Salehyan, C. Hendrix, J. Hamner, C. Case, C. Linebarger, E. Stull, J. Williams, Int. Interact. 38, 503-511 (2011).

10. H. Goemans, K. Gleditsch, G. Chiozza, ARCHIGOS: A Data Set on Leaders 18752004 (2009).

11. I. Salehyan, C. Hendrix, Social Conflict Analysis Database (SCAD) v. 3.3 (2017).

12. C. Sullivan, J. of Conflict Resolution 60, 1163-1190 (2016).

13. B. Martin, Justice Ignited: The Dynamics of Backfire (Rowman \& Littlefield, 2007).

14. C. Davenport, Ann. Rev. Polit. Sci. (2007).

15. M. Belgioioso, J. of Peace Research 55, 641-655 (2018).

16. E. Chenoweth, K. Schock, Mobilization 20, 427-451 (2015).

17. G. Acharya, The People Want: A Radical Exploration of the Arab Uprising (Univ. of Calif. Press, 2013).

18. K. Dalacoura, Int. Affairs 88, 63-79 (2012).

19. P. Collier, A. Hoeffler, Coup Traps: Why Does Africa Have so Many Coups d'etat? Working paper, Oxford Univ. (2015).

20. World Bank, World Development Indicators (World Bank, 2018).

21. J. Fearon, D. Laitin, Am. Pol. Sci. Rev. 97, 75-90 (2003).

22. M. Hvistendahl, Science 333, 552-554 (2011).

23. D. LaGraffe, J. of Strategic Security 5, 65-80 (2012).

24. R. Nordås, C. Davenport, Am. J. of Polit. Sci. 57: 926-940 (2013).

25. J. Bamert, F. Gilardis, F. Wasserfallen, Research and Politics 2, 1-9 (2015).

26. J. Pinckney, When Civil Resistance Succeeds: Lessons for Building Democracy after Nonviolent Popular Uprisings (Int. Center on Nonviolent Conflict, 2018).

27. M. Rivera, K. Gleditsch. J. of Peace Research 50, 385-400 (2013).

28. M. Bayer, F. Bethke, D. Lambach. 2016. J. of Peace Research 53, 758-771 (2016).

Acknowledgements: The authors thank Dara Kay Cohen, Jessica di Salvatore, Christoph Dworschak, Cullen Hendrix, Douglas Johnson, Zoe Marks, Evan Perkoski, Kathryn Sikkink, Teddy Svoronos, Piero Vianello, and participants in a Research Colloquium at the Carr Center for Human Rights Policy for their input, as well as Adam Tischner and participants in the 2014 James Lawson Institute for conversations that helped to inspire this study.

Author contributions: E.C. derived the idea and collected and coded data on the dependent variable. M.B. produced the compiled dataset. M.B. and E.C. formulated the hypothesis, designed the research, performed the analyses, produced the tables and graphs, discussed the results, and provided input to the manuscript. 
Funding: The authors received no specific funding for this work.

Competing interests: The authors declare no competing interests.

\section{Figure legends:}

Figure 1: The association between velocity and irregular leader exit at different values of mass. The figure plots the predicted probability of leader irregular exit (y axis) at different values of velocity of nonviolent dissent ( $\mathrm{x}$ axis) and different levels of mass. All other variables are held at their means. Momentum (a function of mass times velocity) is significantly correlated with the probability of irregular leader exit (coefficient $=.004 ; p=0.003 ; n=16,420$ ). We generated this figure using the marginsplots function in STATA, based on Model 4. The bars indicate $95 \%$ confidence intervals, although these are artificial because Stata calculates them using the delta approach and so ought not be interpreted as numerically meaningful. We used the conditional logit model because it produces more conservative statistical estimates. However, we used conditional logit (rather than rare events conditional logit) regression because rare events logistic regression models preclude the visualization of two-variable marginal effects.

Figure 2. The association between velocity on irregular leader exit at quantiles of mass (logged). The figure plots the effect of velocity on the probability of leader irregular exit (y axis) at different values of velocity (x axis) and different quantile values of mass of nonviolent dissent. All other variables are held at their means. Momentum (a function of mass times velocity) is significantly correlated with the probability of irregular leader exit (coefficient=.004; $\mathrm{p}<.001 ; \mathrm{n}=13,969)$. We generated this figure using the marginsplots function in STATA, based on Model 6. For ease of interpretation, we report the raw values of mass as percentage of the total national population rather than the logged mass indicator. The bars indicate $95 \%$ confidence intervals, although these are artificial because Stata calculates them 
using the delta approach and so ought not be interpreted as numerically meaningful. We use the conditional logit model because it produces more conservative statistical estimates. However, we use conditional logit (rather than rare events conditional logit) regression because rare events logistic regression models preclude the visualization of two-variable marginal effects. 


\section{Tables}

Table 1. Irregular leader exits in Africa, 1990-2014

\begin{tabular}{|c|c|c|c|c|}
\hline $\begin{array}{l}\text { Country } \\
\text { Name }\end{array}$ & $\begin{array}{l}\text { Leader } \\
\text { Name }\end{array}$ & Date of Exit & Mechanism of Exit & $\begin{array}{l}\text { Primary Agents } \\
\text { / Defectors }\end{array}$ \\
\hline Mali & Traore & 26-Mar-91 & $\begin{array}{l}\text { Removed by military in the } \\
\text { midst of popular protests }\end{array}$ & military \\
\hline Ethiopia & $\begin{array}{l}\text { Gebre } \\
\text { Kidan }\end{array}$ & 27-May-91 & $\begin{array}{l}\text { Removed by rebels in the } \\
\text { midst of worker protests }\end{array}$ & rebels \\
\hline Algeria & Benjedid & 11-Jan-92 & $\begin{array}{l}\text { Removed by military amidst } \\
\text { election-related protests }\end{array}$ & military \\
\hline Nigeria & Shonekan & 17-Nov-93 & $\begin{array}{l}\text { Removed by military in the } \\
\text { midst of a worker's strike }\end{array}$ & military \\
\hline Lesotho & Mokhehle & 17-Aug-94 & $\begin{array}{l}\text { Removed by government } \\
\text { actors }\end{array}$ & $\begin{array}{l}\text { government } \\
\text { elites }\end{array}$ \\
\hline Sierra Leone & Strasser & 17-Jan-96 & Removed by military & military \\
\hline Niger & Ousmane & 27-Jan-96 & Removed by military & military \\
\hline Sierra Leone & Kabbah & 25-May-97 & Removed by military & military \\
\hline $\begin{array}{l}\text { Guinea- } \\
\text { Bissau }\end{array}$ & Vieira & 7-May-99 & Removed by military & military \\
\hline Cote d'Ivoire & $\begin{array}{l}\text { Konan } \\
\text { Bedie } \\
\end{array}$ & 25-Dec-99 & Removed by military & military \\
\hline Cote d'Ivoire & Guei & 25-Oct-00 & Popular protest & unknown \\
\hline $\begin{array}{l}\text { Dem. Rep. of } \\
\text { the Congo }\end{array}$ & $\begin{array}{l}\text { Laurent } \\
\text { Kabila }\end{array}$ & 16-Jan-01 & Removed by military & military \\
\hline Madagascar & Radsiraka & 6-Jul-02 & $\begin{array}{l}\text { Removed by government } \\
\text { actors }\end{array}$ & $\begin{array}{l}\text { government } \\
\text { elites }\end{array}$ \\
\hline $\begin{array}{l}\text { Central } \\
\text { African } \\
\text { Republic }\end{array}$ & Patasse & 15-Mar-03 & $\begin{array}{l}\text { Removed by rebels / military } \\
\text { officers in the midst of recent } \\
\text { protests }\end{array}$ & military \\
\hline $\begin{array}{l}\text { Guinea- } \\
\text { Bissau }\end{array}$ & $\begin{array}{l}\text { Kumba } \\
\text { Iala }\end{array}$ & 14-Sep-03 & Removed by military & military \\
\hline Mauritania & $\begin{array}{l}\text { Sidi } \\
\text { Ahmed } \\
\text { Taya }\end{array}$ & 3-Aug-05 & Removed by military & military \\
\hline Mauritania & $\begin{array}{l}\text { Ould } \\
\text { Cheikh } \\
\text { Abdellahi } \\
\end{array}$ & 6-Aug-08 & Removed by military & military \\
\hline Madagascar & $\begin{array}{l}\text { Marc } \\
\text { Ravaloma } \\
\text { nana } \\
\end{array}$ & 17-Mar-09 & Removed by military & military \\
\hline Guinea & $\begin{array}{l}\text { Dadis } \\
\text { Camara }\end{array}$ & 5-Dec-09 & Removed by military & military \\
\hline Tunisia & $\begin{array}{l}\text { Zine Al- } \\
\text { Abidine } \\
\text { Ben Ali }\end{array}$ & 14-Jan-11 & Popular protest & police \\
\hline
\end{tabular}




\begin{tabular}{llrll}
\hline Egypt & Mubarak & 11-Feb-11 & Popular protest & military \\
\hline & Laurent & & & \\
Cote d'Ivoire & Gbagbo & 11-Apr-11 & Removed by military & military \\
\hline Egypt & Morsi & 3-Jul-13 & Popular protest & military \\
\hline Burkina Faso & Traore & 1-Nov-14 & Removed by military & military \\
\hline
\end{tabular}


Table 2. Correlates of irregular leader exit

\begin{tabular}{|c|c|c|c|c|c|}
\hline VARIABLES & $b$ & SE & P-value & $\mathrm{Cl}$ low & $\mathrm{Cl}$ high \\
\hline \multicolumn{6}{|c|}{ Model 1} \\
\hline Velocity & -0.012 & 0.008 & 0.130 & -0.028 & 0.004 \\
\hline Mass & -0.074 & 0.061 & 0.224 & -0.194 & 0.045 \\
\hline Momentum & 0.003 & 0.001 & 0.005 & 0.001 & 0.006 \\
\hline Change in locations & 0.057 & 0.020 & 0.005 & 0.018 & 0.096 \\
\hline Repression (lag) & 2.234 & 0.477 & 0.000 & 1.299 & 3.169 \\
\hline Total state population (logged) & -0.308 & 0.297 & 0.300 & -0.890 & 0.274 \\
\hline GDP per capita (logged) & -0.139 & 0.278 & 0.617 & -0.684 & 0.406 \\
\hline Constant & -3.605 & 4.162 & 0.386 & -11.762 & 4.552 \\
\hline Observations & 290,694 & & & & \\
\hline \multicolumn{6}{|c|}{ Model 2} \\
\hline Velocity (strict) & -0.013 & 0.012 & 0.272 & -0.035 & 0.01 \\
\hline Mass (strict) & -0.078 & 0.066 & 0.234 & -0.208 & 0.051 \\
\hline Momentum (strict) & 0.003 & 0.001 & 0.064 & -0.000 & 0.005 \\
\hline Change in locations & 0.054 & 0.02 & 0.006 & 0.015 & 0.092 \\
\hline Repression (lag) & 2.339 & 0.331 & 0.000 & 1.691 & 2.988 \\
\hline Total state population (logged) & -0.34 & 0.306 & 0.266 & -0.939 & 0.259 \\
\hline GDP per capita (logged) & 0.007 & 0.278 & 0.979 & -0.537 & 0.552 \\
\hline Constant & -5.931 & 4.966 & 0.232 & -15.664 & 3.803 \\
\hline Observations & 291,771 & & & & \\
\hline \multicolumn{6}{|c|}{ Model 3} \\
\hline Number of violent events & 0.005 & 0.226 & 0.983 & -0.437 & 0.447 \\
\hline Velocity & -0.011 & 0.008 & 0.199 & -0.027 & 0.006 \\
\hline Mass & -0.077 & 0.059 & 0.192 & -0.192 & 0.039 \\
\hline Momentum & 0.003 & 0.001 & 0.005 & 0.001 & 0.005 \\
\hline Change in locations & 0.055 & 0.021 & 0.009 & 0.014 & 0.096 \\
\hline Repression (lag) & 2.278 & 0.467 & 0.000 & 1.363 & 3.192 \\
\hline
\end{tabular}




\begin{tabular}{|c|c|c|c|c|c|}
\hline Total state population (logged) & -0.292 & 0.291 & 0.317 & -0.863 & 0.279 \\
\hline GDP per capita (logged) & -0.134 & 0.283 & 0.636 & -0.690 & 0.421 \\
\hline Constant & -3.788 & 4.504 & 0.400 & -12.616 & 5.039 \\
\hline Observations & 290,694 & & & & \\
\hline \multicolumn{6}{|l|}{ Model 4} \\
\hline Momentum & 0.004 & 0.001 & 0.008 & 0.001 & 0.007 \\
\hline Velocity & -0.018 & 0.022 & 0.432 & -0.061 & 0.026 \\
\hline Mass & -0.118 & 0.065 & 0.070 & -0.246 & 0.010 \\
\hline Change in locations & 0.033 & 0.022 & 0.126 & -0.009 & 0.076 \\
\hline Repression (lag) & 1.375 & 0.582 & 0.018 & 0.235 & 2.516 \\
\hline Total state population (logged) & -0.472 & 0.431 & 0.274 & -1.316 & 0.373 \\
\hline GDP per capita (logged) & -0.079 & 0.277 & 0.775 & -0.623 & 0.464 \\
\hline Constant & -0.238 & 5.463 & 0.965 & -10.946 & 10.469 \\
\hline Observations & 16,420 & & & & \\
\hline \multicolumn{6}{|l|}{ Model 5} \\
\hline Momentum (strict) & 0.003 & 0.001 & 0.011 & 0.001 & 0.006 \\
\hline Velocity (strict) & -0.015 & 0.019 & 0.436 & -0.051 & 0.022 \\
\hline Mass (strict) & -0.113 & 0.072 & 0.113 & -0.254 & 0.027 \\
\hline Change in locations & 0.033 & 0.016 & 0.038 & 0.002 & 0.065 \\
\hline Repression (lag) & 1.377 & 0.567 & 0.015 & 0.266 & 2.488 \\
\hline Total state population (logged) & -0.491 & 0.353 & 0.164 & -1.184 & 0.201 \\
\hline GDP per capita (logged) & 0.032 & 0.315 & 0.920 & -0.586 & 0.650 \\
\hline Constant & -1.850 & 6.407 & 0.773 & -14.407 & 10.708 \\
\hline Observations & 17,497 & & & & \\
\hline \multicolumn{6}{|l|}{ Model 6} \\
\hline Momentum (based on logged mass) & 0.018 & 0.006 & 0.005 & 0.006 & 0.030 \\
\hline Velocity & -0.180 & 0.081 & 0.026 & -0.339 & -0.022 \\
\hline Mass (logged) & -0.376 & 0.157 & 0.017 & -0.684 & -0.068 \\
\hline Change in locations & 0.041 & 0.044 & 0.355 & -0.046 & 0.128 \\
\hline Repression (lag) & 1.452 & 1.163 & 0.212 & -0.827 & 3.730 \\
\hline
\end{tabular}




\begin{tabular}{|c|c|c|c|c|c|}
\hline Total state population (logged) & -0.953 & 0.609 & 0.117 & -2.146 & 0.240 \\
\hline GDP per capita (logged) & -0.085 & 0.670 & 0.899 & -1.399 & 1.228 \\
\hline Constant & 12.822 & 8.477 & 0.130 & -3.792 & 29.437 \\
\hline Observations & 13,969 & & & & \\
\hline \multicolumn{6}{|l|}{ Model 7} \\
\hline Momentum (based on strict mass logged) & 0.014 & 0.008 & 0.058 & -0.000 & 0.029 \\
\hline Velocity (strict) & -0.154 & 0.096 & 0.107 & -0.342 & 0.033 \\
\hline Mass (strict; logged) & -0.241 & 0.264 & 0.362 & -0.759 & 0.277 \\
\hline Change in locations & 0.036 & 0.052 & 0.487 & -0.066 & 0.139 \\
\hline Repression (lag) & 1.345 & 0.945 & 0.155 & -0.508 & 3.197 \\
\hline Population (logged) & -0.744 & 0.629 & 0.237 & -1.978 & 0.489 \\
\hline GDP per capita (logged) & 0.230 & 0.898 & 0.798 & -1.530 & 1.990 \\
\hline Constant & 0.313 & 12.720 & 0.980 & -24.618 & 25.244 \\
\hline Observations & 13,258 & & & & \\
\hline \multicolumn{6}{|l|}{ Model 8} \\
\hline Number of violent events & 0.033 & 0.053 & 0.532 & -0.070 & 0.136 \\
\hline Constant & -9.334 & 0.660 & 0.000 & -10.628 & -8.039 \\
\hline Observations & 411,601 & & & & \\
\hline
\end{tabular}

Note: Time dependency control included. 